\title{
The Residual Potential of Bottom Water Reservoir Based upon Genetic Algorithm for the Relative Permeability Inversion
}

\author{
Dong Zhang, Jie Tan, Dongdong Yang, Songru Mu, Qin Peng \\ Bohai Oilfield Research Institute, Tianjin Branch of CNOOC Ltd., Tianjin, China \\ Email: yangdd@cnooc.com.cn
}

How to cite this paper: Zhang, D., Tan, J., Yang, D. D., Mu, S. R., \& Peng, Q. (2019). The Residual Potential of Bottom Water Reservoir Based upon Genetic Algorithm for the Relative Permeability Inversion. Journal of Geoscience and Environment Protection, 7, 192-201.

https://doi.org/10.4236/gep.2019.74012

Received: March 27, 2019

Accepted: April 21, 2019

Published: April 24, 2019

Copyright $\odot 2019$ by author(s) and Scientific Research Publishing Inc. This work is licensed under the Creative Commons Attribution International License (CC BY 4.0).

http://creativecommons.org/licenses/by/4.0/

(c) (i) Open Access

\begin{abstract}
At present in the offshore oilfield, $X$ oilfield had successfully developed bottom water reservoir with horizontal well. The development mode of single sand body of horizontal well caused water cut rose rapidly and irresistible bottom water coning. The common empirical formula of recoverable reserves obtained through statistical analysis was not applicable to the bottom water reservoir. Under the condition of as high as tens of thousands of time local scour multiple, underground seepage law had been changed. In order to improve the understanding of the remaining potential of bottom water reservoir in the ultra-high water cut stage, this research innovation proposed to carry out the flow tube simulation of the bottom water ridge. In addition, combining with the theoretical research of the quantitative characterization of the water ridge form and the vector permeability, theoretical model was established. At last, the phase permeability curve was calculated from the production data of the ultra-high water cut stage of the bottom water reservoir by combining the genetic algorithm. According to the change of water ridge and oil saturation, the mechanism of end point change of phase permeability curve was expounded, and the effective production radius of water drive oil in bottom water reservoir was put forward, which provided the basis for understanding the potential of oil field and tapping the potential in the future.
\end{abstract}

\section{Keywords}

Bottom Water Reservoir, Water Coning Radius, Genetic Algorithm, Water Cut, The Relative Permeability

\section{Introduction}

The bottom water reservoir of $\mathrm{x}$ oilfield had the characteristics of high crude oil 
viscosity, low oil column height and sufficient bottom water energy. The development mode of single sand body of horizontal well was adopted, which caused water cut rise rapidly in horizontal production wells and bottom water coning irresistible. When the oil well entered the ultra-high water cut stage, the sweeping volume tended to be stable, and the main way to improve oil recovery rate was to improve oil displacement efficiency. At present, $x$ Oilfield Group was in the stage of ultra-high water cut and $68 \%$ of production wells had water cut more than $90 \%$. The dynamic characteristics of production wells showed that the water cut of horizontal wells in the bottom water reservoir rised rapidly, the recoverable reserves were mainly produced after high water cut period, and the cumulative oil production in the stage of extra-high water cut accounts for $60 \%$ $70 \%$ of the recoverable reserves. Therefore, the development characteristics of the bottom water reservoir showed that the extra-high water cut stage was an important development stage of this reservoir type.

At present, the problem was that the common empirical formula of recovery rate in oilfield was mainly obtained through statistical analysis, and all calculation parameters were applicable within a certain range (Permadi \& Jayadi, 2010). However, the viscosity, permeability and well pattern density of crude oil in $\mathrm{x}$ oilfield were not applicable to the empirical formula, so there was no reliable conclusion on recovery rate (Kuchuk, 1988). In the actual development process of the oilfield, the local scour multiple index was as high as tens of thousands (Gao, Jiang, Wang, et al., 2016; Zheng, 1993). With the increase of pore volume injection multiple, the oil displacement efficiency in the swept area could be further improved, due to large differences of residual oil saturation acquired by laboratory test and actual condition. Under the condition of high scour, the end point of residual oil saturation must shift to the right, so the relative permeability curve needs to be further modified, and the final understanding of water drive efficiency needs further theoretical study.

\section{Theoretical Model Establishment and Analysis of Bottom Water Reservoir}

\subsection{Quantitative Characterization of Bottom Water Ridge}

The flow of horizontal wells in bottom water reservoir was shown in Figure 1. The hypothesis was: 1) Oil-water two-phase fluid seepage in reservoir; 2) Uniform reservoir thickness; 3 ) Reservoir fluid percolation conforms to Darcy's law; 4) Reservoir rocks were anisotropic and heterogeneous; 5) Regardless of capillary pressure; 6) Regardless of gravity (Fan, 1993; Zheng, Xu, \& Chen, 2013).

According to the basic formula of the balance principle of statics:

$$
\Delta p=-\Delta \rho_{w o} g \Delta z
$$

The relationship between the height of water ridge and the radius of water ridge could be obtained through the corresponding differentiation and integration:

$$
z=-\frac{q \mu_{o}\left(1-f_{w}\right)}{2 \pi K K_{r o} \Delta \rho_{w o} g} \frac{\ln R_{e} / r_{w}}{R_{e} z_{\max }} \ln \left(1-\frac{z_{\max } \ln R_{e} / r_{w}}{h \ln R_{e} / r_{w}}\right)
$$




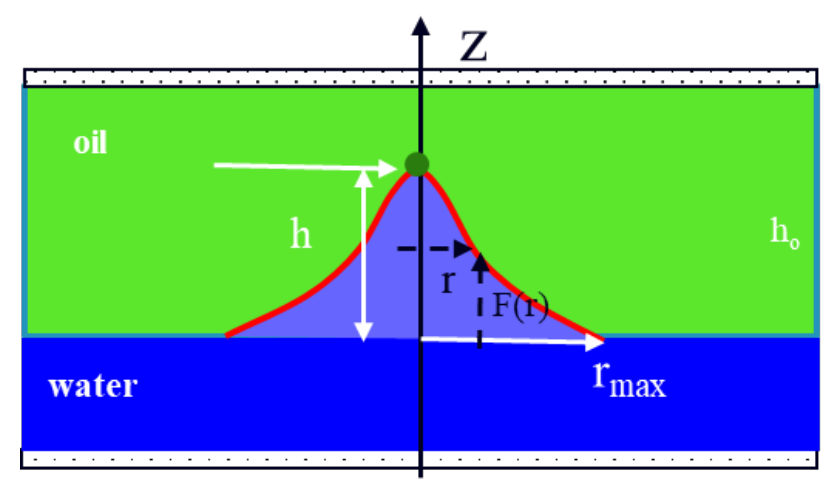

Figure 1. Bottom water ridge of horizontal well in bottom-water reservoir.

By integrating, the following formula was proposed:

$$
z=z_{\max }-\frac{q \mu_{w} f_{w}}{2 \pi K K_{r w} \rho_{w} g}\left(\frac{1}{r_{w}}-\frac{1}{r}\right)
$$

Through the above formula, the height under different water ridge radius could be calculated, as well as the distribution and remaining oil quantity.

\subsection{Vector Characteristics and Calculation Method of Directional Reservoir Permeability}

Research and production practice showed that permeability had obvious directionality, so permeability was vector (Xin, 2011; Li, Zhou, Xiong, et al., 2015). The directional difference of permeability will directly affect the well arrangement, well spacing and the technical design of various development measures such as artificial fracturing. In view of the above important role of vector permeability, based on previous studies, this paper introduced the reasons for the vector characteristics of rock permeability, and analyzed some understandings that were easy to be confused when understanding and applying the vector characteristics of permeability (Liu \& Hu, 2011, Chen \& Tao, 1997; Bing, 2012).

As shown in Figure 2, OB was the azimuth reference line (the azimuth of $\mathrm{OB}$ was $0^{\circ}$, generally taking the due east direction as the azimuth reference line); in the derivation process, the $X$ and $Y$ axes of the coordinate system were consistent with the direction of the extreme permeability, and the extreme permeability in the x-axis direction was $K_{m x}$. The extreme permeability in y direction was $K_{m ;} ; \nabla P_{n}$ was the displacement pressure gradient in $\mathrm{n}$ direction; A was the area of the vertical seepage section perpendicular to $\nabla P_{n} ; \nabla P_{n}$ was displacement of fluids. The displacement effect of $x$ component $\nabla P_{n x}$ and $y$ component $\nabla P_{n y}$ on fluid. The above principle was called equivalent displacement principle. If $Q_{x}$ was used to express the flow of fluid through section a in $X$ direction under the action of $\nabla P_{n x}$. The flow rate of fluid through section a in $Y$ direction under the action of $\nabla P_{n y}$ was expressed by $Q_{y}$, According to the equivalent displacement principle, Flow $Q$ through seepage section a under the action of, Should be

$$
Q_{n}=Q_{x}+Q_{y}
$$




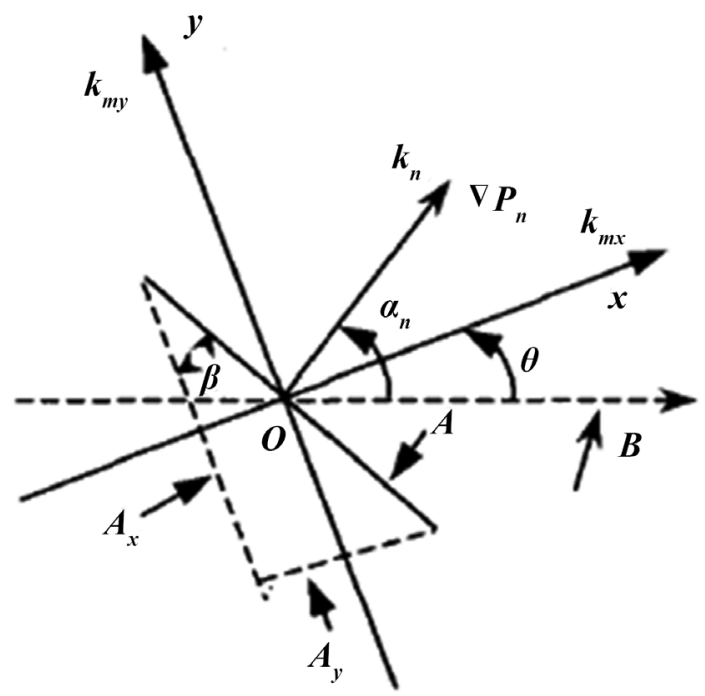

Figure 2. Derivation of permeability calculation model.

Derivation of quantitative calculation model of vector permeability. Using $K_{n}$ to express permeability in $\mathrm{n}$ direction; Fluid seepage velocity in the direction of $V_{n}: \mu$ was the viscosity of the fluid, according to Darcy's law.

$$
V_{n}=-\frac{K_{n}}{\mu} \nabla P_{n}
$$

Then the flow through seepage section $A$ is:

$$
Q_{n}=A V_{n}=-A \frac{K_{n}}{\mu} \nabla P_{n}
$$

As shown in Figure 3, Use $A_{x}$ to express the effective seepage area of section $A$ in $z$ direction (that was the seepage area perpendicular to $x$ direction); $\alpha_{n}$ was the azimuth of direction $n ; \theta$ represents the azimuth of the extreme permeability $K_{m x}$ that is, the azimuth of the $x$-axis. Because the two sides of the $\beta$ angle and the two sides of the $\alpha_{n}-\theta$ angle were perpendicular to each other, so $\beta$ be equal to $\alpha_{n}-\theta$, so:

$$
A_{x}=A \cos \beta=A \cos \left(\alpha_{n}-\theta\right)
$$

Similarly, the effective seepage area of interface a in $Y$ direction (that was, the seepage area perpendicular to $Y$ direction was

$$
A_{y}=A \sin \beta=A \sin \left(\alpha_{n}-\theta\right)
$$

The component $\nabla P_{n}$ in the $X$ direction was:

$$
\nabla P_{n x}=\nabla P_{n} \cos \left(\alpha_{n}-\theta\right)
$$

Under the action of $\nabla P_{n x}$, the seepage velocity of fluid passing through section a in $X$ direction was:

$$
V_{x}=-\frac{K_{m x}}{\mu} \nabla P_{n x}
$$

You could get it by combining 


$$
Q_{x}=-A \frac{K_{m x}}{\mu} \nabla P_{n} \cos ^{2}\left(\alpha_{n}-\theta\right)
$$

Simplify to:

$$
K_{n}=K_{m x} \cos ^{2}\left(\alpha_{n}-\theta\right)+K_{m y} \sin ^{2}\left(\alpha_{n}-\theta\right)
$$

The above formula was the quantitative calculation model of anisotropic permeability.

Where $K_{n}$ was the permeability in $\mathrm{n}$ direction; $K_{m x}$ was the extreme permeability in the $x$-axis direction; $K_{m y}$ was the extreme permeability in the $y$-axis direction; $\alpha_{n}$ was the azimuth of direction $n ; \theta$ was the azimuth of the extreme permeability $K_{m x}$.

\subsection{Distribution Pattern and Grid Division of Stream in Water Ridge Area of Bottom Water Reservoir}

The gas oil ratio was low in $X$ Oilfield, the water ridge profile of horizontal well could be simplified as oil-water two-phase flow chart, as shown in Figure 3. After the production well entered the ultra-high water cut period, the sweep area was stable. The flow pipe model could be used to simulate the oil-water two-phase flow in the sweep area through the quantitative characterization of water ridge shape (Sun, Zhou, Hu, et al., 2018, Yan, Li, Yin, et al., 2009; Chen, Bai, Lu, et al., 2015).

The flow tube model assumed that the immiscible displacement process still followed the same streamline when the homogeneous fluid in the porous medium was stable. According to the flow line of single-phase fluid flow in the early stage, the simulation could be divided into multiple flow tubes. The linear displacement model was used to simulate the immiscible displacement in the flow tube. The dynamic of this region was simulated by combining the dynamic of all the flow tubes that made up this region in the same time. For each flow tube, the

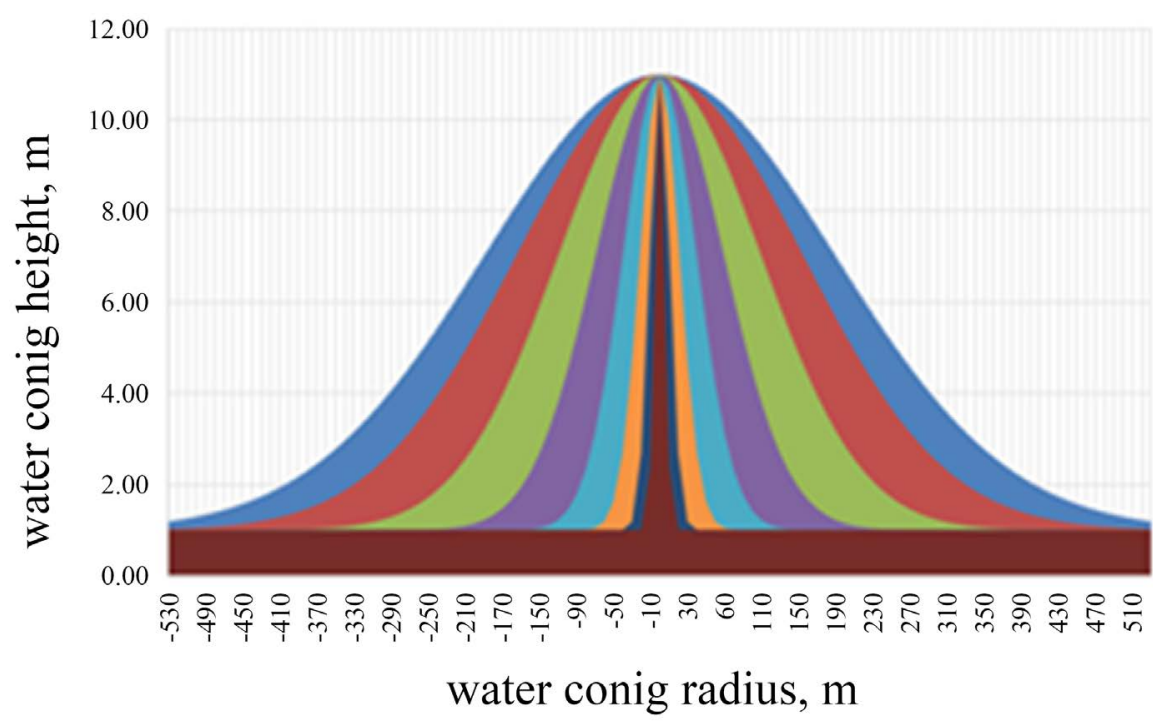

Figure 3. Mesh generation of water coning in bottom-water reservoir. 
simulation mainly included the solution of forward propulsion equation, the solution of total flow, and the solution of the relationship between total flow and the timing.

According to the two-dimensional seepage theory, the streamline distribution of stable condition was obtained. Assume that the streamline was constant, the displacement path of bottom water was obtained. In the process of displacement, the displacement space of bottom water was expanding along the horizontal direction.

In the flow tube model established by Higgins and Leighton, the flow tube was divided into $N$ equal volume grids. For each production step, displacement process of simulation by advancing saturation of water drive front, until the water breakthrough occurs in the $\mathrm{n}$ grid. Finally, by combining the result of different flow tubes in the same injection time value, we could get the total dynamic state of all flow tubes in the same injection production well.

The solution steps of Higgins-Leighton method were as follows: the streamline and flow pipe distribution was determined in single-phase flow, for each flow tube, cumulative water injection multiple was given; Calculating the saturation distribution and average apparent viscosity distribution corresponding to each flow tube; Calculating the total flow volume in the flow pipe; Calculating the corresponding time value; Summarizing the results of each flow pipe in the same injection time value for getting the total flow dynamics. According to the streamline distribution of the bottom water area, equal volume grid was the principle of dividing.

\subsection{Realization of Bottom Water Drive Model Calculation Program}

The model was calculated by MATLAB software, this software was a high level programming language widely used in the field of engineering calculation and numerical analysis. It had strong numerical calculation function, which was easy to learn and easy to operate. The software was divided into one core solver and four modules, which included that data processing module, equal volume mesh module, water drive front saturation tracking module, post-processing module, data input and processing module.

\section{Genetic Algorithm Coupled with Bottom Water Flooding Theory Model}

\subsection{The Form of the Permeability Curve Expressed}

Usually, the phase permeability curve was expressed as follows:

$$
k_{r w}=k_{r w} S_{o r} \cdot\left(S_{w}^{*}\right)^{C_{w}} ; k_{r o}=k_{r o} S_{w i} \cdot\left(1-S_{w}^{*}\right)^{C_{o}}
$$

where, $S_{w}$, water saturation; $S_{w i}$ irreducible water saturation; $S_{o r}$, residual oil saturation; $k_{r o} S_{w i}$, the initial maximum oil relative permeability; constant $C_{w}$

$C_{o}$, refer to oil phase index and water phase index, $S_{w}^{*}=\frac{S_{w}-S_{w i}}{1-S_{w i}-S_{o r}}$. The phase 
permeability curve could be well fitted according to formula (13).

\subsection{The Method of Genetic Algorithm (GA)}

Genetic algorithm was a computational model simulating the natural selection and genetic mechanism of Darwinian evolution. It was a method to search the optimal solution by simulating the natural evolution (Yin, Zhao, Dong, et al., 2012). Taking small bubbles of different colors and sizes as examples, in order to find bubbles of specific colors and sizes, it was necessary to optimize the initial number of small bubbles (survival and elimination), and then produce a new group of small bubbles after genetic calculation until the optimal solution was found.

In this paper, the genetic algorithm was coupled with the bottom water drive model. Different characteristic parameter of relative permeability curve was generated through initial population, and theoretical curves were calculated by the theoretical model between water cut and recovery degree. The optimal solution with minimum of forecast error was determined compared with the actual production data, as shown in Figure 4.

\subsection{Calculation Results of Genetic Algorithm Coupled with Theoretical Model of Bottom Aquifer Drive}

The residual oil saturation was 0.05 by the optimized infiltration curve, as shown in Figure 5, which was lower than the original oil saturation. This indicates that the oil displacement efficiency in the affected area can be greatly improved depending on the high PV in the ultra-high water cut stage of the bottom water reservoir. Further analysis shows that the optimized curve reflects the stronger hydrophilic property of the reservoir, as a result of isopermeability point shifts to the right.

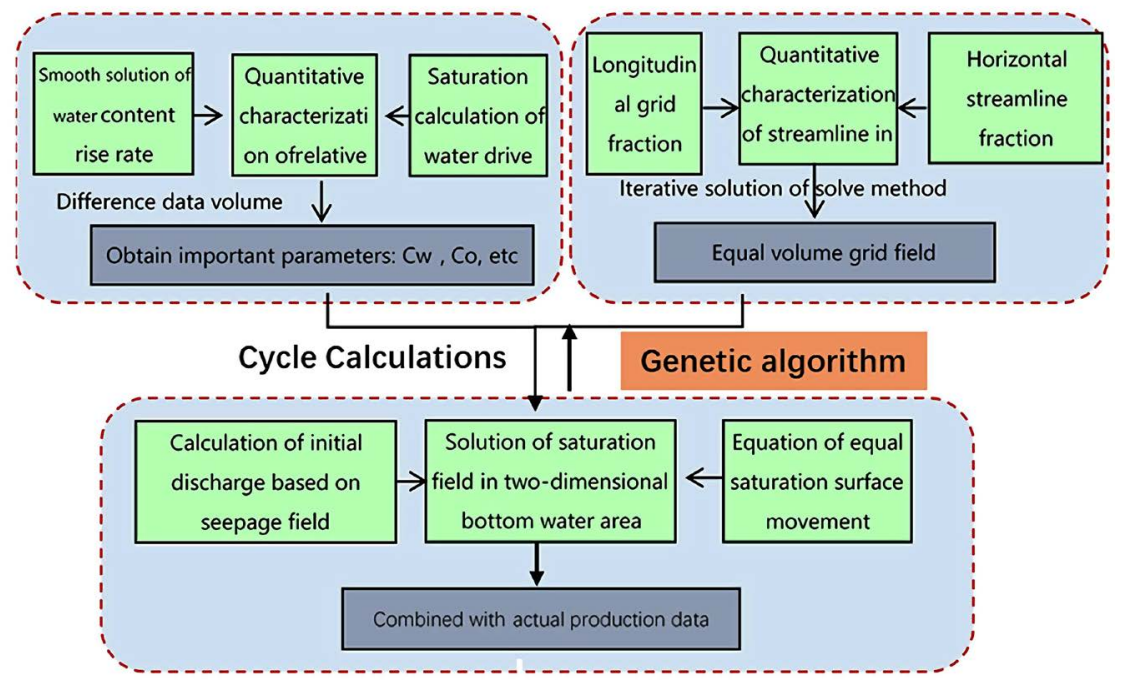

Figure 4. Flow chart of the research coupling genetic algorithm and bottom-water drive mode. 


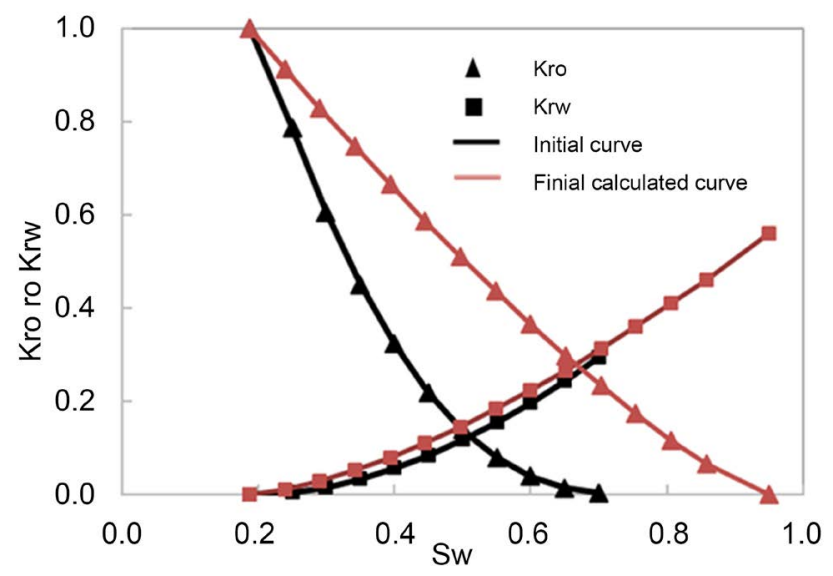

Figure 5. Calculation result of optimized relative permeability curve based on genetic algorithm.

\section{Method Application and Recognition}

\subsection{Distribution Characteristics of Micro Remaining Oil in Bottom Water Reservoir}

Through the bottom water drive model, the distribution rule of remaining oil under the condition of constant pressure difference/constant flow rate can be realized. From Figure 6, it can be seen that the bottom water wave and area within the production range of oil layer present the "inverted V" shape, and the production well had the fastest water flow in the vertical direction, which was the dominant mainstream line, and its flow was far greater than the edge area.

It could be seen from the figure that there were obvious differences in oil displacement efficiency in the affected area. The vertical direction of production wells was reflected as "dominant channel", and the scour multiple was higher than 1000 times. It could be seen from the figure that under the high porosity volume injection multiple, the oil displacement efficiency was the highest. Through this model, the quantitative characterization of the remaining oil spatial difference could be realized.

\subsection{Effective Production Radius of Water Drive in Bottom Water Reservoir}

Based on the quasi streamline method, the bottom water drive model of oil-water two-phase homogeneous horizontal well was established, which could realize the quantitative characterization of bottom water wave and remaining oil in the area, under the condition of constant pressure difference and constant flow rate, as well as the difference analysis of parameters such as injection multiple of pore volume and displacement efficiency in the affected area. On this basis, the concept of effective production radius of bottom water drive reservoir was put forward for the first time. Minimum distance of interference between wells was obtained. In addition, the theoretical template of effective production radius of horizontal well under different fluid properties and water avoiding height was given, as shown in Figure 7, which further enriches the development boundary of 


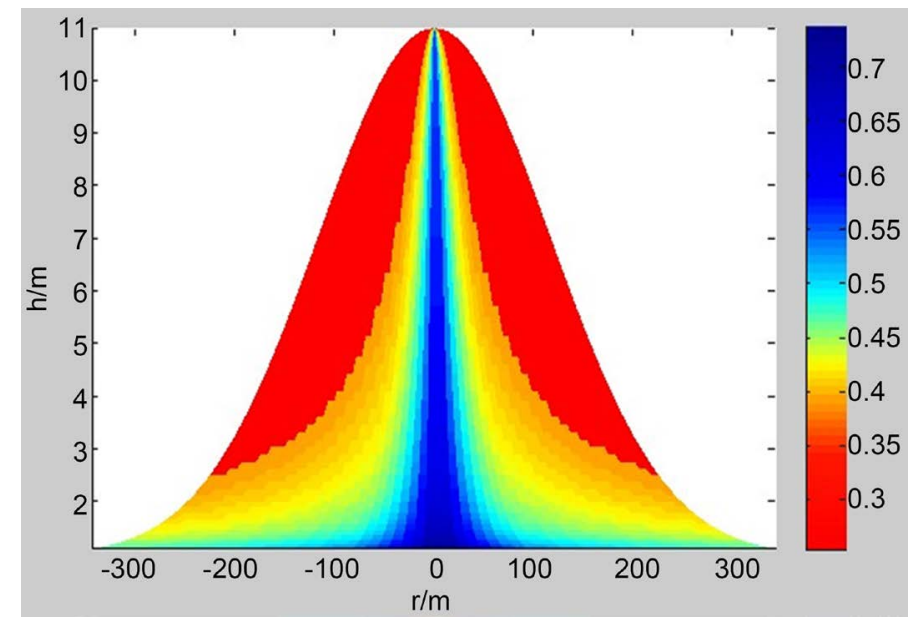

Figure 6. Residual oil distribution of bottom water drive model.

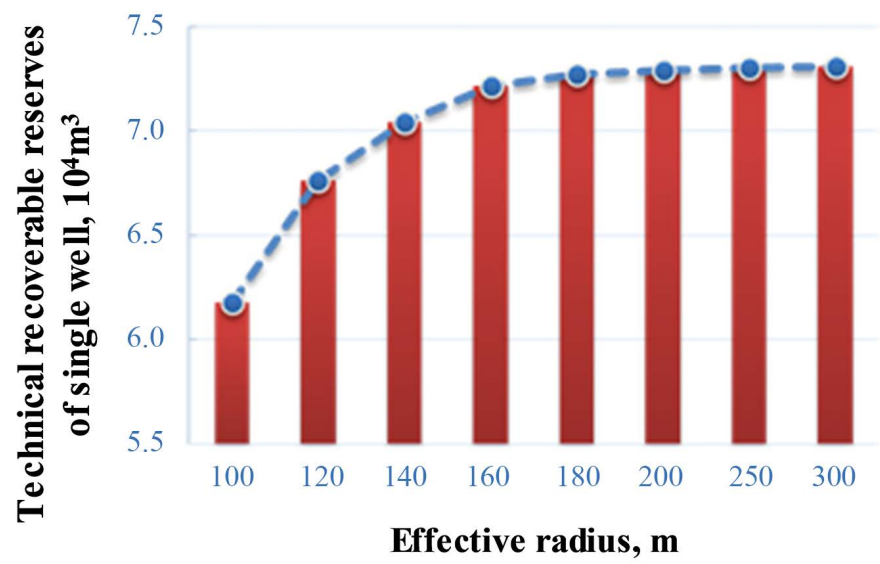

Figure 7. The recoverable reserves of single well under different production radius with crude oil viscosity $142 \mathrm{mPa} \cdot \mathrm{s}$.

bottom water reservoir and provides guidance for further development and adjustment of oilfield.

\section{Conclusion}

1) Combined with Genetic algorithm and the flow tube simulation of the bottom water, the phase permeability curve was calculated from the production data of the ultra-high water cut stage for the bottom water reservoir.

2) The residual oil saturation by the optimized infiltration curve was lower than the original oil saturation, indicating that the oil displacement efficiency in the affected area can be greatly improved depending on the high PV in the ultra-high water cut stage of the bottom water reservoir.

3) Through the bottom water drive model, the distribution rule of remaining oil under the condition can be obtained, and the theoretical template of effective production radius of horizontal well under different fluid properties and water avoiding height was given, in order to provide guidance for further development and adjustment of oilfield. 


\section{Conflicts of Interest}

The authors declare no conflicts of interest regarding the publication of this paper.

\section{References}

Bing, S. X. (2012). Study on Relative Permeability Equation Adapted at Ultra-High Water-Cut Stage. Journal of Oil and Gas Technology, 34, 18-20.

Chen, B., Bai, Z. H., Lv, J. W. et al. (2015). Study on Relationship between Sedimentary Microfacies and Water Flooding Pore Volume as Well as Remaining Oil: Taking Lower V Oil Layers in Shuanghe Oilfield as an Example. Journal of Xi'an Shiyou University (Natural Science Edition), 30, 53-58.

Chen, Y. Q., \& Tao, Z. Q. (1997). Derivation of Water Drive Cure at High Water-Cut Stage and Its Analysis of Upwarding Problem. Fault-Block Oil \& Gas Field, 4, 19-24.

Fan, Z. F. (1993). The Research of Horizontal Well Productivity Formula in Bottom Water Drive Reservoir. Petroleum Exploration and Development, 20, 71-75.

Gao, Y. J., Jiang, H. Q., Wang, S. L. et al. (2016). Numerical Simulation of Microscopic Water-Oil Displacement Based on Level Set Finite Element Method. China Offshore Oil and Gas, 6, 39-42.

Kuchuk, F. J. (1988). Pressure Transient Analysis for Horizontal Wells. In SPE Annual Technical Conference and Exhibition (SPE-18300-MS). Houston: Society of Petroleum Engineers. https://doi.org/10.2118/18300-MS

Li, L. F., Zhou, F. X., Xiong, J. H. et al. (2015). Quantitative Evaluation Method of Water Flooded Degree of Oil Reservoirs Developed by Horizontal Wells and Its Application. Journal of Xi'an Shiyou University (Natural Science Edition), 5, 59-63.

Liu, X. Y., \& Hu, P. (2011). A 3D Visible Physical Experiment on Horizontal Wells of Heterogeneous Reservoirs with Bottom Water. Acta Petrolei Sinica, 32, 1012-1016.

Permadi, P., \& Jayadi, T. (2010). An Improved Water Coning Calculation for Horizontal well. In SPE Russian Oil and Gas Conference and Exhibition (SPE-133162-RU). Houston: Society of Petroleum Engineers. https://doi.org/10.2118/133162-RU

Sun, Q., Zhou, H. Y., Hu, Y. et al. (2018). Calculation Method of Area Sweep Efficiency of Non-Piston Water Flooding for Inverted 9-Spot Pattern. Complex Hydrocarbon Reservoirs, $11,52-56$.

Xin, C. P. (2011). Quantitative Description of Water Cone and Study on the Well Pattern Optimization in Bottom Water Reservoir. Wuhan: China University of Petroleum (East China).

Yan, W. L., Li, Z. C., Yin, S. J. et al. (2009). A New Method to Determine Original Oil Saturation in Oil-Water Layer. Well Logging Technology, 33, 440-443.

Yin, J. L., Zhao, D. N., Dong, J. S. et al. (2012). Numerical Simulation on Factors Affecting Flooding Mechanism of Bottom Water Reservoir in Horizontal Wells. PGRE, 19, 90-92.

Zheng, H. Y. (1993). A Method of Determining Average Water and Oil Relative Permeiability Curves. China Offshore Oil and Gas, 7, 45-52.

Zheng, K., Xu, H. M., \& Chen, J.-W. (2013). Study on Tong's B-Type Water Drive Characteristics Empirical Formula. Journal of China University of Petroleum, 37, 99-108. 